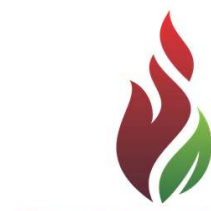

SUSTENERE

Publishing Corporation

\section{LICENCIAMENTOS AMBIENTAIS E AVALIAÇÕES DE IMPACTOS AMBIENTAIS DO SETOR SUCROENERGÉTICO: ASPECTOS MULTIDISICPLINARES}

\section{RESUMO}

Este trabalho visa discutir a importância e o uso da multidisciplinaridade e da interdisciplinaridade no Licenciamento Ambiental (LA) e nas Avaliações de Impactos Ambientais (AIA) do setor sucroalcooleiro no estado de Mato Grosso do Sul (MS). O objetivo é identificar os perfis e atribuições dos técnicos e profissionais envolvidos em sua elaboração e análise, além dos órgãos responsáveis pela sua aprovação. Trata-se de um estudo exploratório e descritivo com a utilização de dados da CANASAT/INPE, MAPA e IMASUL. Realizou-se análise de algumas normas e legislações ambientais, federal e estadual, pertinentes ao licenciamento ambiental e aos estudos e relatórios de impactos ambientais (EIA/RIMA) do setor sucroalcooleiro do estado. Os dados e as discussões permitiram constatar que as Avaliações de Impactos Ambientais (AIA) e os Licenciamentos Ambientais (LA) são elaborados e analisados, tanto no âmbito federal, quanto no âmbito estadual, de forma multidisciplinar, visando à prevenção, solução, recuperação e/ou manutenção do meio ambiente.

PALAVRAS-CHAVES: Governança Ambiental; Estudos de Impactos Ambientais; Interdisciplinaridade e Multidisciplinaridade.

\section{ENVIRONMENTAL LICENSING AND ENVIRONMENTAL IMPACT ASSESSMENTS OF THE SUGARCANE INDUSTRY: ASPECTS MULTIDISICPLINARES}

\section{ABSTRACT}

The article discusses the importance and the use of multidisciplinary and interdisciplinary in Environmental Licensing (EL) and the Environmental Impact Assessments (EIA) of the sugar and alcohol sector in the state of Mato Grosso do Sul (MS). The goal is to identify the profile and duties of technicians and professionals involved in its preparation and analysis in addition to the bodies responsible for its approval. This is an exploratory and descriptive study using data from CANASAT / INPE, MAP and IMASUL. We conducted analysis of some standards and environmental laws, federal and state, relevant to environmental licensing and studies and environmental impact reports of the state of this sector. The data and discussions showed that it Assessments of Environmental Impact (AEI) and Environmental Licensing (EL), are developed and analyzed, both at federal and at the state level, in a multidisciplinary way, aimed at prevention, solution, recovery and / or maintaining the environment.

KEYWORDS: Environmental Governance; Environmental Impact Studies; Interdisciplinary and Multidisciplinary.
Revista Ibero-Americana de

Ciências Ambientais, Aquidabã, v.6, n.2, Jun, Jul, Ago, Set, Out, Nov 2015.

ISSN 2179-6858

\section{SECTION: Articles}

TOPIC: Legislação Ambiental

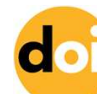

DOI: $10.6008 / S P C 2179-6858.2015 .002 .0002$

Elioterio Fachin Dias

Universidade Estadual de Mato Grosso do Sul, Brasil http://lattes.cnpq.br/1184991657784352 elioterio@uems.br

Erlaine Binotto

Universidade Federal da Grande Dourados, Brasil http://lattes.cnpq.br/5823505442014380 ErlaineBinotto@ufgd.edu.br

Luciana Ferreira da Silva

Universidade Estadual de Mato Grosso do Sul, Brasil http://lattes.cnpq.br/6097823498734817 lucianafsilva@uol.com.br

Received: 06/05/2015

Approved: 21/10/2015

Reviewed anonymously in the process of blind peer.

Referencing this:

DIAS, E. F.; BINOTTO, E.; SILVA, L. F.. Licenciamentos ambientais e avaliações de impactos ambientais do setor sucroenergético: aspectos multidisicplinares. Revista Ibero-Americana de Ciências Ambientais, Aquidabã, v.6, n.2, p.23-36, 2015. DOI: http://dx.doi.org/10.6008/SPC21796858.2015 .002 .0002 


\section{INTRODUÇÃO}

A questão ambiental e suas interfaces com a sustentabilidade impulsionaram movimentos importantes, leis e arranjos institucionais para tratar e efetivar a governança ambiental. Essa problemática constitui um campo de pesquisa aglutinador de disciplinas especializadas, envolvendo a análise de processos biológicos, físicos, químicos, hidrológicos, entre outros. Nesse sentido, "é, por definição, um estudo que requer um enfoque interdisciplinar do relacionamento e da interdependência entre seres humanos e natureza" (PHILIPPI JUNIOR et al., 2013, p.518). A Política Nacional do Meio Ambiente (PNMA) estabelecida pela Lei $n^{\circ}$ 6.938/1981, objetiva a preservação, a melhoria e a recuperação da qualidade ambiental propícia à vida, visando assegurar no País, condições ao desenvolvimento socioeconômico, aos interesses da segurança nacional e à proteção da dignidade da vida humana (BRASIL, 1981).

A Avaliação de Impactos Ambientais (AIA) e o Licenciamento Ambiental (LA) são alguns dos instrumentos da PNMA e pela Resolução do Conselho Nacional do Meio Ambiente (CONAMA) $n^{\circ}$ 001/1986, que dispõe sobre os critérios básicos e as diretrizes para o uso e a implementação do Estudo de Impacto Ambiental (EIA) e do Relatório de Impacto Ambiental (RIMA), que permitem identificar, analisar e quantificar os prováveis impactos relevantes, e definir as possíveis medidas mitigadoras dos impactos negativos. A Resolução Conama 001/1986 dispõe que o Licenciamento Ambiental depende da elaboração do EIA/RIMA, que serão submetidos à aprovação do órgão ambiental competente, o Instituto Brasileiro de Meio Ambiente e Recursos Renováveis (IBAMA), se, de competência federal; ou, dos órgãos estaduais ou municipais, nas respectivas competências (CONAMA, 1986).

No MS, o Decreto n 12.231/2007 estabelece a competência sobre a execução da Política Estadual de Meio Ambiente em todo o seu território, passando pelo crivo do Instituto de Meio Ambiente de Mato Grosso do Sul (IMASUL), a aprovação dos licenciamentos ambientais e do EIA/RIMA (MS, 2007). Nas últimas décadas, o setor sucroalcooleiro brasileiro tem se destacado como pioneiro na produção de biocombustível economicamente viável, popularmente chamada de bioenergia. Da mesma forma, o MS apresenta significativo crescimento, ocupando a posição de quinto maior produtor nacional de cana-de-açúcar, com considerável aumento de licenciamentos ambientais de usinas de açúcar e álcool (LACERDA \& ALMEIDA, 2014).

A Lei $n^{\circ} 3.404 / 2007$ dispõe que as unidades industriais que venham a ser instaladas no estado dependerão de EIA/RIMA, o que pressupõe prévio licenciamento ambiental do empreendimento (MS, 2007a). Para Maranhão (2010), essas questões complexas e multidisciplinares, além de produzir novos conhecimentos científicos, e responder às emergências e às demandas sociais do mundo em transformação, exigem a cooperação entre profissionais de diferentes formações, de modo interdisciplinar. Este trabalho visa discutir a importância e o uso da multidisciplinaridade e da interdisciplinaridade no Licenciamento Ambiental (LA) e nas Avaliações de Impactos Ambientais (AIA) do setor sucroalcooleiro no estado de Mato Grosso do Sul, cujo 
objetivo é identificar os perfis e atribuições dos técnicos e profissionais envolvidos em sua elaboração e análise e os órgãos responsáveis pela sua aprovação.

\section{REVISÃO TEÓRICA}

\section{Os Licenciamentos Ambientais, a Interdisciplinaridade e a Multidisciplinaridade: O Licenciamento Ambiental e o EIA/RIMA}

O licenciamento ambiental é considerado, hoje, o principal instrumento de política nacional do meio ambiente (SANTAMARINA \& CUNHA NETO, 2010). A Lei 6.938/1981 e as Resoluções CONAMA 001/1986 e 237/1997 conceituam-no como um procedimento pelo qual o órgão ambiental licencia a localização, a instalação, a ampliação e a operação de empreendimentos e das atividades consideradas efetiva ou potencialmente poluidoras, ou que possam causar degradação ambiental (BRASIL, 1981; CONAMA, 1986, 1997). O licenciamento ambiental se compõe das seguintes licenças: licença prévia (LP), licença de instalação (LI) e licença de operação (LO). A LP é concedida na fase preliminar de planejamento, aprova a localização e a concepção do empreendimento ou atividade, atestando a viabilidade ambiental e estabelecendo os requisitos básicos $\mathrm{e}$ as condicionantes a serem cumpridas nas próximas fases do empreendimento, obra ou atividade. A LI autoriza a instalação do empreendimento ou atividade de acordo com as especificações constantes dos planos, programas e projetos aprovados, incluindo as medidas de controle ambiental e demais condicionantes. A LO autoriza a operação da atividade ou do empreendimento, após a constatação do efetivo cumprimento das medidas de controle ambiental e condicionantes definidos nas licenças anteriores (BRASIL, 1981; CONAMA, 1986, 1997).

Os empreendimentos e as atividades ligadas ao setor sucroalcooleiro, ou seja, aquelas relativas à fabricação de combustíveis não derivados de petróleo (indústrias químicas), e à fabricação e refino de açúcar (indústrias de produtos alimentares e bebidas), também estão sujeitos ao licenciamento ambiental (CONAMA, 1997). O Estudo de Impacto Ambiental é essencial porque contempla todas as alternativas tecnológicas e de localização do projeto, identifica e avalia sistematicamente os impactos ambientais gerados nas fases de implantação e operação da atividade; além de definir os limites da área geográfica a ser afetada pelos impactos ambientais (CONAMA, 1986).

Segundo Pegado e Barbosa (2013), o EIA, que serve de base para a análise do licenciamento ambiental, deve ser elaborado por uma equipe multidisciplinar, envolvendo profissionais dos diversos ramos do saber, devidamente cadastrados nos órgãos ambientais. O Relatório de Impacto Ambiental (RIMA) deve ser escrito em linguagem clara e direta, com análise pormenorizada dos impactos ambientais do projeto e de suas alternativas, previsão da magnitude e interpretação da importância dos prováveis impactos positivos e negativos (benéficos e 
adversos), diretos e indiretos, imediatos e a médio e longo prazo, temporários e permanentes; grau de reversibilidade. Deve ainda, definir as medidas mitigadoras dos impactos negativos, os equipamentos de controle e sistemas de tratamento de despejos, com avaliação de eficiência; além de elaborar o programa de acompanhamento e monitoramento dos impactos positivos e negativos (CONAMA, 1986).

\section{A Gestão Ambiental no Estado de Mato Grosso do Sul}

A gestão ambiental no Brasil se fundamenta na Política Nacional do Meio Ambiente (PNMA), que estabelece conceitos, princípios, objetivos, instrumentos, penalidades, mecanismos de formulação e aplicação, no intuito de estabelecer normas de gestão e proteção dos recursos ambientais (BARROS, et al., 2012).

A gestão ambiental é o conjunto de ações que visa à definição e a aplicação de normas ambientais e ecológicas sujeitas às atividades humanas, objetivando a preservação do meio ambiente. Surge da necessidade de identificar e mensurar eventos e transações ambientais, contribuindo para o processo de tomada de decisões, procurando amenizar os impactos das atividades empresariais (OLIVEIRA, 2014; PÁDUA \& DORNELES, 2014). A gestão ambiental em Mato Grosso do Sul iniciou-se formalmente, com a criação do Instituto de Preservação e Controle Ambiental (INAMB), por meio do Dec.-Lei $n^{0}$ 09/1979, autarquia vinculada à Secretaria de Desenvolvimento Econômico. O INAMB foi o primeiro órgão, de âmbito estadual, com atuação especifica na área ambiental, tendo como atribuição a execução da política de uso e conservação dos recursos naturais, bem como de preservação e controle ambiental (BARROS \& GARCIA, 2014).

Em 2 de junho de 1980, foi aprovada a Lei estadual n 90, dispondo sobre as alterações do meio ambiente, Estabelecendo que o lançamento de quaisquer substâncias na água, no solo ou no ar, por fontes industriais, comerciais, agropecuárias e outras, órgãos governamentais ou particulares, deveria ser precedido de autorização do Conselho Estadual de Controle Ambiental (CECA), instruída por parecer de técnico do INAMB. Órgão esse, extinto pela Lei estadual $n^{\circ}$ 702/1987, que criou a Secretaria de Meio Ambiente de Mato Grosso do Sul (SEMA), a quem competia licenciar e revisar as atividades potencialmente poluidoras, monitorar, fiscalizar as atividades e promover programas e projetos relacionados à gestão da política de meio ambiente e do controle da qualidade dos recursos hídricos (MS, 1980; 1987).

Em 21 de dezembro de 1993, foram criadas as Fundações Terceiro Milênio - Pantanal (FEMAP) e Terceiro Milênio - Natureza Viva, por meio das leis estaduais $n^{0} 1.463$ e 1465, respectivamente, com a finalidade de executar a Política Ambiental no estado. Cabia à FEMAP controlar e fiscalizar a utilização racional dos recursos naturais, nas áreas que constituem o Pantanal sul-mato-grossense. A Fundação Terceiro Milênio - Natureza Viva, por sua vez, tinha por atribuições, formular e propor políticas de uso racional, promover e incentivar pesquisas e 
integrar políticas públicas e privadas. Em 1998, essas fundações fundiram-se, através da Lei estadual $n^{\circ} 1829$, de 16 de janeiro, criando a Fundação Estadual de Meio Ambiente - Pantanal (Fema-P), vinculada à Secretaria de Estado de Meio Ambiente e Desenvolvimento Sustentável (SEMADES), assumindo todas as competências das anteriores (BARROS \& GARCIA, 2014).

Em 9 de julho de 2001, foi editada a Lei estadual $n^{0} 2.257$, que estabeleceu as diretrizes do licenciamento ambiental estadual, conferindo à Fundação Estadual de Meio Ambiente Pantanal, a emissão das seguintes Licenças Ambientais: Licença Prévia (LP), Licença de Instalação (LI), e Licença de Operação (LO), e das Autorizações Ambientais (AA). No mesmo ano, com base na Lei estadual $n^{\circ} 2.268$, de 31 de julho, a Fema-P era transformada em autarquia e passava a denominar-se Instituto de Meio Ambiente - Pantanal (Imap), mantendo as mesmas atribuições e competências da anterior. Em 22 de dezembro de 2006, a Lei estadual $n^{\circ} 3.345$ criou a Secretaria de Meio Ambiente, das Cidades, do Planejamento, da Ciência e Tecnologia (SEMAC), como responsável pela gestão ambiental e de recursos hídricos; e, também, o Instituto de Meio Ambiente de Mato Grosso do Sul (IMASUL), cabendo-lhe coordenar e executar a política de meio ambiente em todo o território estadual.

Cabe ao IMASUL, dentre outras atribuições: conceder o licenciamento ambiental e realizar o controle de obras, empreendimentos e atividades efetivas ou potencialmente poluidoras e ou modificadores do meio ambiente (MS, 2009). A estrutura organizacional do IMASUL, representada pelo organograma constante do Dec. $n^{\circ} 13.988 / 2014$, apresenta as Gerências de Licenciamento Ambiental, Gerência de Recursos Florestais, Gerência de Recursos Hídricos e Gerência de Controle e Fiscalização, todas vinculadas à Diretoria de Licenciamento, conforme Figura 1.

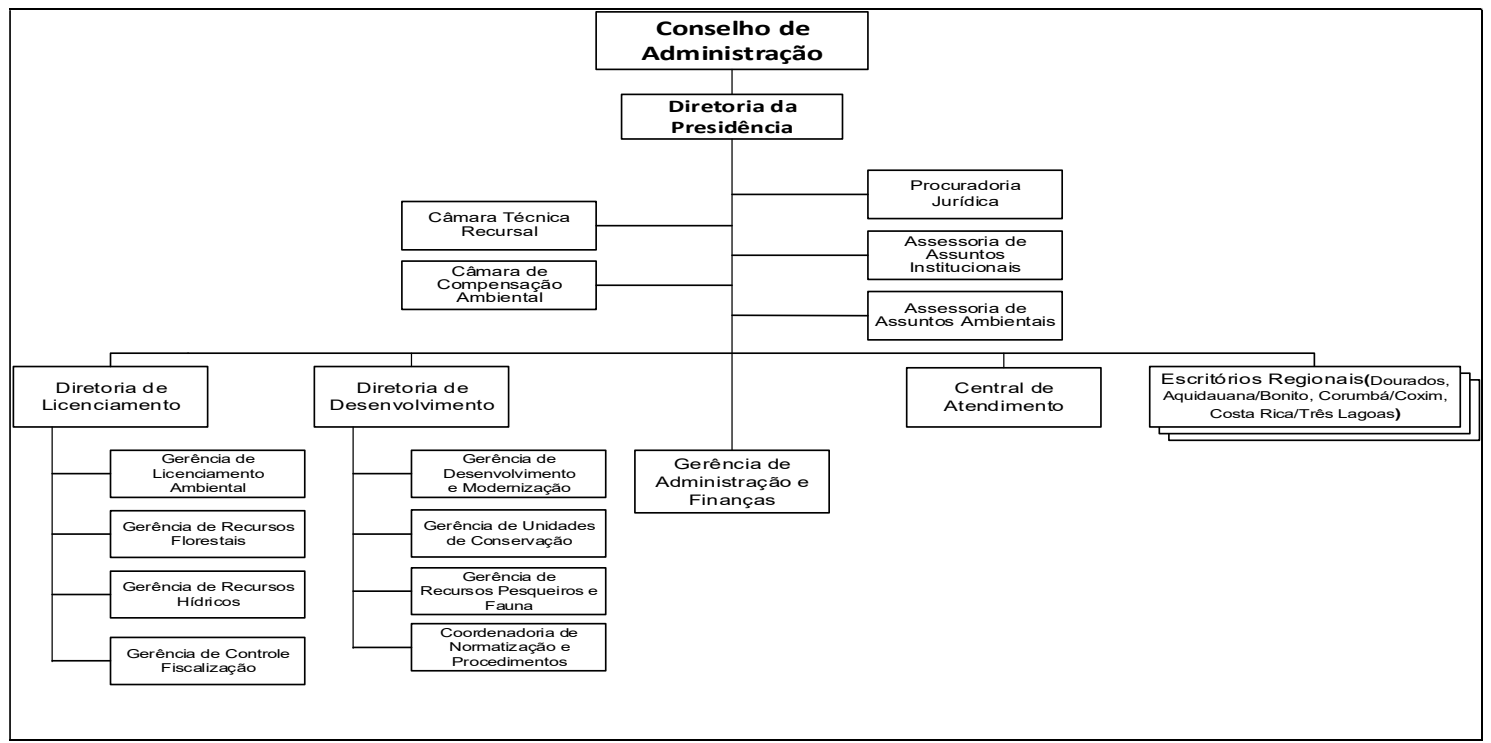

Figura 1: Organograma do IMASUL Fonte: IMASUL, 2014.

Compete à Gerência de Licenciamento Ambiental, dentre outras atribuições: executar o licenciamento ambiental dos empreendimentos efetivos ou potencialmente poluidoras; realizar, em conjunto com a Gerência de Controle e Fiscalização, a execução da fiscalização e do monitoramento dos empreendimentos e atividades licenciados; e, propor medidas de melhoria 
contínua para a gestão do licenciamento ambiental. A Lei estadual $n^{\circ} 4.488$, de 3 de abril de 2014 , que reestrutura o quadro de pessoal do IMASUL, e dispõe sobre a reorganização da carreira de Fiscalização e Gestão Ambiental estabelece as atribuições dos cargos de Fiscais e Analistas, a quem compete: planejar, propor, promover e executar a fiscalização, regulação, controle, licenciamento, perícia e auditoria ambiental, monitoramento e ordenamento dos recursos ambientais, hídricos e da qualidade do ar (MS, 2014).

Além de definir as atividades básicas dos cargos, as competências, e as atribuições técnicas e operacionais, a lei estabelece também, a quantidade de quatrocentos e cinqüenta (450) cargos efetivos: cento e oitenta (180) fiscais ambientais; sessenta (60) analistas ambientais; sessenta (60) técnicos ambientais; cinquenta (50) técnicos em serviços ambientais; e, cem (100), guardas parque.

\section{A Multidisciplinaridade e a Interdisciplinaridade do Meio Ambiente}

O meio ambiente, por ser uma temática abrangente e complexa, não se limita a conceitos ou definições estanques e fragmentados, possuindo inúmeras interfaces e inter-relações que afetam o fenômeno social, político e econômico. Segundo Padilha (2010), o conhecimento científico produzido do meio ambiente é um conhecimento que será afetado pela multidisciplinaridade. Os problemas ambientais vêm aumentando significativamente em importância, constituindo-se em objeto de pesquisas extremamente complexas, que necessitam da multidisciplinaridade, elemento importante para sua resolução, em todas as suas esferas (MARANHÃO, 2010; MEDEIROS et al., 2014).

Para Deponti (2013), a multidisciplinaridade é o tratamento de uma temática comum por diferentes disciplinas percebidas de forma individual ou disciplinar, que fornecem uma síntese. Já, a interdisciplinaridade é uma inter-relação entre várias disciplinas. Uma problemática geral em que as várias disciplinas constroem a análise interdisciplinar a partir da articulação e da interação conjunta, estabelecendo interfaces entre elas. A interdisciplinaridade é de fundamental importância na análise e na resolução dos problemas ambientais, constituindo a articulação de várias disciplinas, tendo como foco, o objeto, o problema ou o tema complexo, não bastando a resposta de uma só área. É um processo de diálogo entre disciplinas estabelecidas em sua identidade teórica e metodológica, conscientes de seus limites (CARNEIRO, 1995; MINAYO, 2010; RAYNAUT, 2011).

A abordagem interdisciplinar consiste em colocar especialistas em várias áreas do conhecimento para juntos buscarem entender problemas reais ou abstratos. Busca-se a interação entre disciplinas, superando-se a compartimentação cientifica provocada pela excessiva especialização (BUARQUE, et al., 2014). A interdisciplinaridade e a complexidade exigem a colaboração e a cooperação, que nos desafiam para o exercício de um novo olhar, que distingue e entende a complementaridade (MINAYO, 2010). A complexidade é uma palavra problema e não 
uma solução. Aparece como uma espécie de buraco, de confusão, de dificuldade. Existe quando os elementos diferentes são inseparáveis constitutivos do todo, como o econômico, o político, o sociológico, o psicológico, o afetivo ou o mitológico (MORIN, 2000; 2001).

A prática interdisciplinar de produção de conhecimento é viável, mas difícil, constrangedora e desconfortável, pois obriga a compreender, a avaliar, a aceitar ou a rejeitar procedimentos diferentes e muitas vezes não familiares. Possibilita uma evolução da aplicação de conceitos e métodos de diferentes áreas, gerando algo que não se encaixa perfeitamente em nenhuma delas (RODRIGUES, 2010, MARANHÃO, 2010). Segundo Maranhão (2010), os resultados dessa prática indicam um potencial de complementaridade entre as diversas áreas do conhecimento com relação à questão ambiental. Seu principal desafio consiste nos modos de relacionamento e na ação coletiva, pois envolvem coordenação, cooperação e confiança entre cientistas de diferentes áreas de resolução de problemas complexos que compartilham.

A complexidade ambiental reclama a participação de especialistas de áreas distintas, que trazem pontos de vistas diferentes e complementares - do ecólogo, do geógrafo, do agrônomo, do geomorfólogo, do economista, do sociólogo, do antropólogo ou do historiador, em relação aos ambientes físico e social (LEFF, 2011). Cerca de um terço de todos os programas interdisciplinares trata de alguma questão ambiental, que mesclam algumas das seguintes temáticas: desenvolvimento sustentável, meio ambiente, biodiversidade, recursos naturais e outros focos de interesse, tais como saúde, energia, direito, sociedade, gestão e tecnologia (MARANHÃO, 2010).

Segundo Santa marina e Cunha Neto (2010), as questões ambientais são, em sua grande maioria, multidisciplinares, não existindo uma ideia clara das atribuições profissionais de cada egresso nas diversas denominações de cursos oferecidos pelas instituições de ensino. Para Câmara (2013), a participação da sociedade civil na formulação e execução de políticas públicas vem aumentando e causando mudanças significativas na composição dos atores sociais e dos tomadores de decisão no país, com a proliferação de conselhos, comitês e grupos de trabalho multissetoriais e plurais. O processo de controle e de fiscalização ambiental é realizado por profissionais de diferentes áreas de atuação. Cada processo estará mais protegido, ao passar pelo crivo de comissão técnica multidisciplinar, consideração jurídica ou conselho de representantes da sociedade civil organizada (ALMEIDA NETO et al., 2011; CARVALHO \& MONTEIRO, 2014). A Agenda 21, documento da Conferência da ONU sobre o Meio Ambiente e Desenvolvimento de 1992, destaca sobre a necessidade de fortalecimento das abordagens multidisciplinares visando o desenvolvimento de estudos interdisciplinares entre a comunidade cientifica e tecnológica e os responsáveis por decisões (OLIVEIRA \& SAMPAIO, 2011).

\section{METODOLOGIA}

A metodologia utilizada baseia-se em um estudo exploratório e descritivo com a utilização de dados da CANASAT/INPE, MAPA e IMASUL. Realizou-se análise de algumas normas e 
legislações ambientais, federal e estadual, pertinentes ao licenciamento ambiental e aos estudos e aos relatórios de impactos ambientais (EIA/RIMA) do setor sucroalcooleiro no estado de Mato Grosso do Sul. O presente estudo utiliza dados relativos à área cultivada e colhida de cana-deaçúcar destinada à produção de bioenergia, no Brasil e no estado de Mato Grosso do Sul, a partir da safra 2003/2004, com a introdução dos veículos tipo flex no mercado brasileiro, até a safra 2013/2014. O objeto do estudo centra-se no estado de Mato Grosso do Sul, localizado ao sul da Região Centro-Oeste, considerado o sexto do país em extensão territorial, com uma área de 35.145,532 km², com a população estimada, em 2013, de 2.597.267 habitantes (IBGE, 2013; CASTILHO, 2013; SEMAC/SUPLAN, 2014).

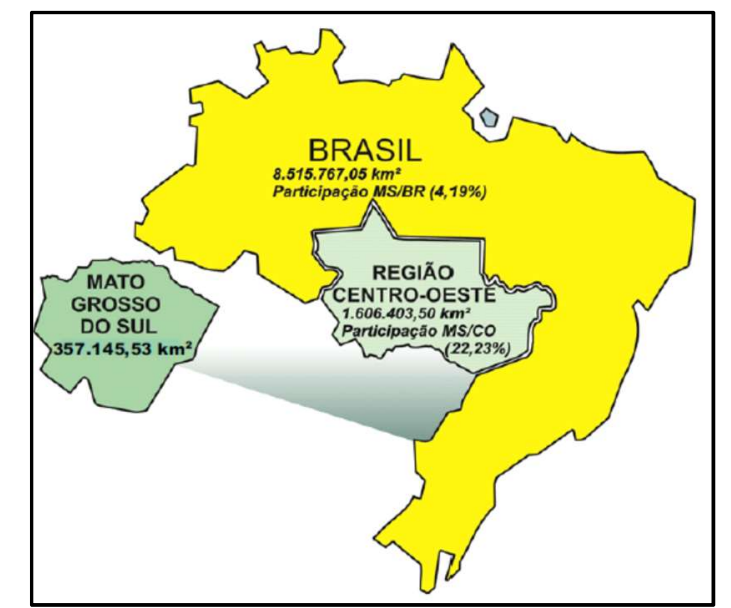

Figura 2: Estado de Mato Grosso do Sul (BR).

Fonte: SEMAC/SUPLAN (2014, p.4).

\section{Análise e Interpretação de Resultados}

Nesta seção, apresentam-se as temáticas: 'A expansão do setor sucroenergético em Mato Grosso do Sul e os licenciamentos ambientais'; 'Normas e procedimentos para os licenciamentos ambientais das usinas de cana em Mato Grosso do Sul', 'A Interdisciplinaridade nos licenciamentos e EIA/RIMA em Mato Grosso do Sul'.

\section{A Expansão do Setor Sucroenergético em Mato Grosso do Sul e os Licenciamentos} Ambientais

No embalo da preocupação mundial com o fenômeno do aquecimento global e impulsionado pela criação da tecnologia flex, o Brasil retomou a produção de etanol oriundo da cana-de-açúcar, se consolidando como o maior produtor mundial de açúcar e etanol, a partir da biomassa da cana-de-açúcar. E, como tal, é líder de produção de cana-de-açúcar, resultado da expansão dessa cultura nas regiões Sudeste, Centro-Oeste e Nordeste; expandindo seu cultivo sobre áreas antes dominadas pela pecuária (LACERDA \& ALMEIDA, 2014). Na safra 2004/2005, o Brasil produziu, na área total de 5,6 milhões de hectares, 385,2 milhões de toneladas de cana- 
de-açúcar; aumentando para 8,8 milhões de hectares de área colhida, na safra de 2013/2014, com a produção total de 658,8 milhões de toneladas de cana-de-açúcar colhidos, destinadas à produção de açúcar, etanol e energia, conforme Figura 3. Da mesma forma, o estado de Mato Grosso do Sul apresentou um significativo crescimento na área cultivada de cana-de-açúcar, no período de 2003/2004 a 2013/2014, o que mostra o grande potencial de expansão do estado, conforme Figura 4.

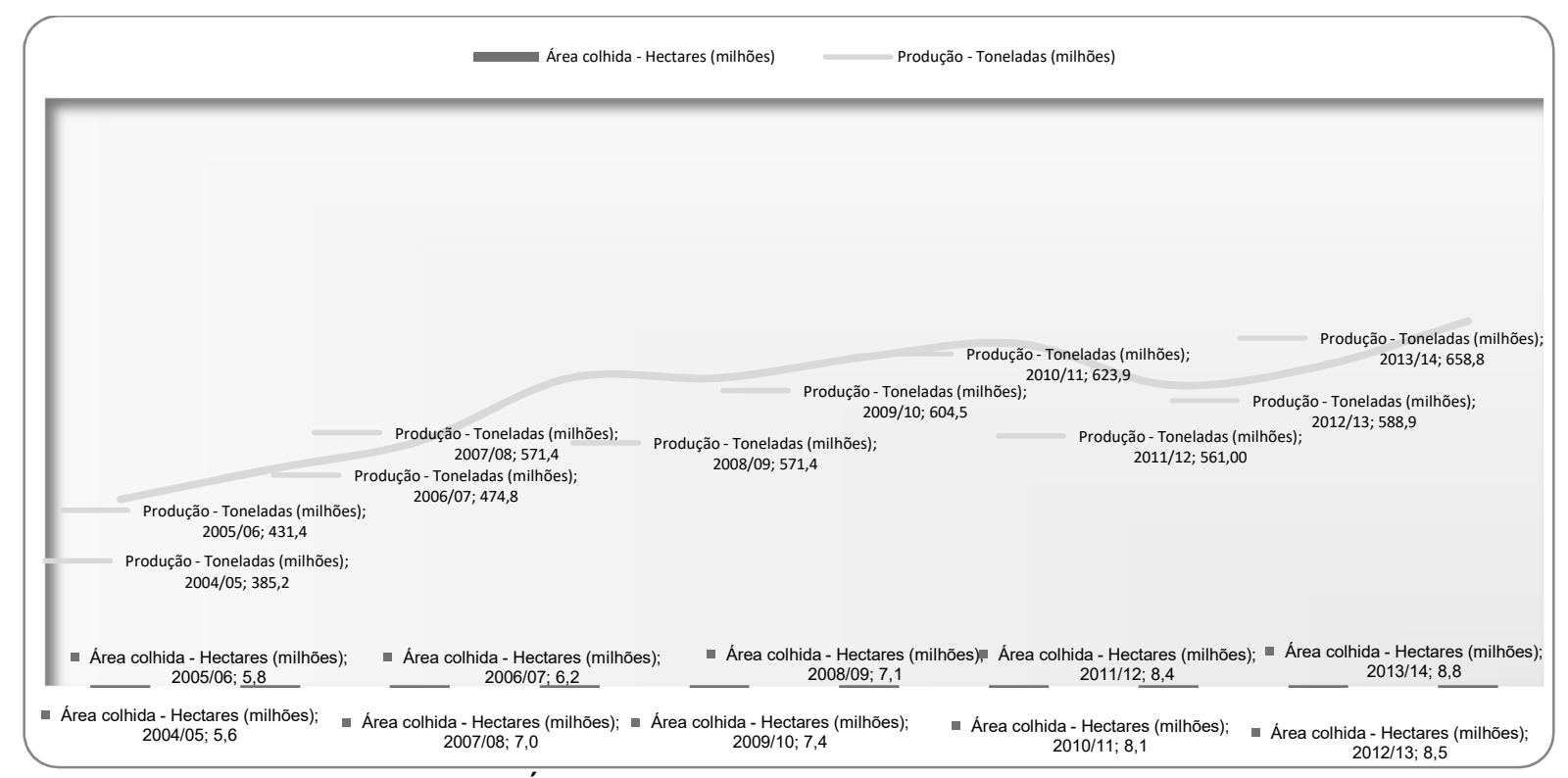

Figura 3: Área e produção de cana-de-açúcar no Brasil Fonte: Adaptado de Neves et al. (2014, p.16)

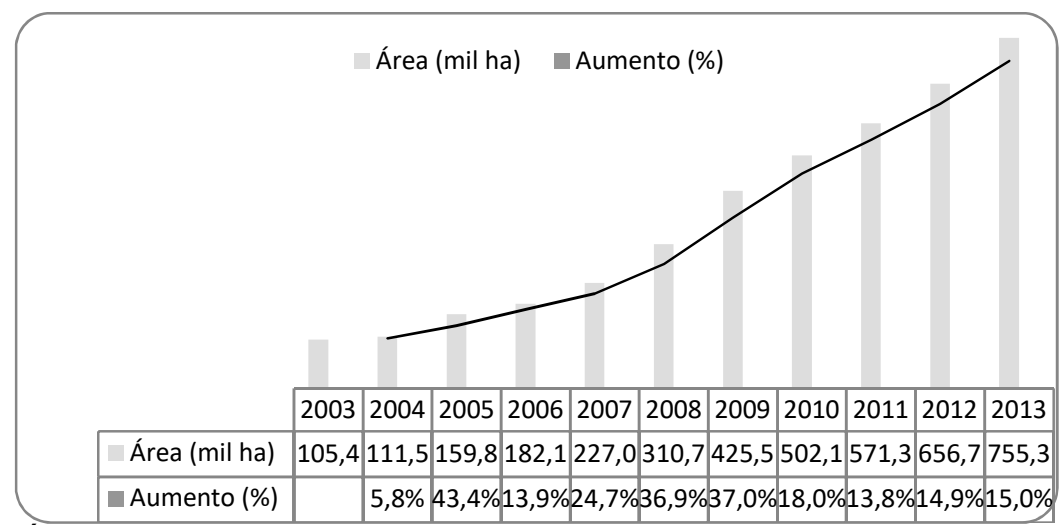

Figura 4: Área cultivada de cana-de-açúcar no Estado de Mato Grosso do Sul (mil/ha).

Fonte: Adaptado de INPE/CANASAT (2015).

É possível observar o avanço acelerado e contínuo do cultivo da cana-de-açúcar no Estado, trazendo benefícios para a economia sul-mato-grossense, impulsionando-lhe o crescimento. Entretanto, incorre em sérios danos para o meio ambiente, quando este avanço ocorre de forma desordenada. Por isso, tanto o licenciamento ambiental, quanto os EIA/RIMA, devem considerar esses impactos, apresentando alternativas, soluções e medidas mitigadoras para essas degradações (PÁDUA \& DORNELES, 2014; LACERDA \& ALMEIDA, 2014). Além das questões ambientais, tecnológicas, sociais, o Estado enfrenta o problema da falta de infra- 
estrutura para o escoamento da produção de álcool. A recomendação principal é que as indústrias do setor apresentem, além do Estudo de Impacto Ambiental, medidas compensatórias nos âmbitos ambiental, social e tecnológico (ZEE/MS, 2008).

\section{Normas para os Licenciamentos das Usinas de Cana em Mato Grosso do Sul}

A Resolução SEMAC $n^{\circ}$ 008, de 31 de maio de 2011, estabelece as normas e procedimentos para o licenciamento ambiental, no âmbito do estado de Mato Grosso do Sul, tendo como diretrizes, dentre outras: considerar simultaneamente os elementos e processos capazes de provocar impacto ambiental; utilizar critérios diferenciados para o licenciamento em função do porte, da complexidade e do potencial do impacto ambiental da atividade; incluir o risco de ocorrência de acidentes, na determinação de restrições e condições para localização, instalação e operação da atividade; avaliar as disposições determinadas no Zoneamento Ecológico-Econômico do Estado de Mato Grosso do Sul (ZEE/MS), no Plano Estadual de Recursos Hídricos (PERH) e no enquadramento dos corpos de água; e, compatibilizar a instalação da atividade pretendida com outros usos e ocupações do solo em seu entorno (MS, 2011).

A Resolução SEMAC $n^{\circ}$ 020, de 25 de outubro de 2007, procura unificar os procedimentos de licenciamento ambiental e executá-los de forma integrada e multidisciplinar toda a legislação ambiental, normas e padrões pertinentes para as atividades de usina de processamento de canade-açúcar, usina de biomassa que objetiva a co-geração de energia elétrica através da queima do bagaço da cana, dentre outras. Determina ainda, que os empreendimentos já implantados ao solicitarem licença ambiental para usina de biomassa deverão apresentar os procedimentos em separado.

Havendo necessidade de captação de água (superficial e/ou subterrânea) e/ou operação de posto de abastecimento de combustíveis durante a fase de implantação da usina de processamento de cana-de-açúcar, a respectiva LO deverá ser requerida em separado, para cada uma das citadas atividades. A co-geração de energia, o canteiro de obras, captação de água (superficial e/ou subterrânea), fertirrigação ou posto de abastecimento de combustíveis deverão ser contemplados nos estudos ambientais da usina de processamento de cana-de-açúcar (MS, 2007).

\section{A multidisciplinaridade e a interdisciplinaridade nos licenciamentos e nos EIARIMA em Mato Grosso do Sul}

No Brasil, observa-se que, quase todas as áreas do conhecimento possuem grupos de pesquisas que trabalham temáticas sobre meio ambiente, desenvolvimento sustentável, biodiversidade e recursos naturais, resultando em práticas interdisciplinares. Essas questões ambientais exigem a cooperação e a integração entre profissionais de áreas diversas e distintas, e 
ocorrem de modo interdisciplinar ou multidisciplinar, na elaboração e análise dos instrumentos de EIA/RIMA elaborados com vistas à concessão do licenciamento ambiental, pelos respectivos órgãos ambientais, no âmbito federal, estadual ou municipal, conforme determinam as legislações e normais ambientais, em suas respectivas jurisdições.

Os procedimentos de licenciamento ambiental são executados e analisados pela Gerência de Licenciamento do IMASUL, de forma integrada e multidisciplinar, pelos fiscais ambientais (biólogos; ecólogos; engenheiros ambientais, agrícolas, agrônomos, cartógrafos, agrimensores, civis, de pesca, elétricos, físicos, florestais e sanitários, entre outros) geólogos, químicos, médicos veterinários e zootecnistas. E, ainda, pelos analistas ambientais (advogados, economistas, contadores, assistentes sociais, analistas de sistemas, geógrafos, turismólogos ou pedagogos).

Os Relatórios de Impactos Ambientais (RIMA) das usinas de processamento de cana-deaçúcar instaladas em Mato Grosso do Sul têm sido elaborados por profissionais de áreas diversas, tais como: advogados, antropólogos, arqueólogos, arquitetos, biólogos, cientistas sociais, economistas, ecólogos, engenheiros (agrimensores, agrônomos, ambientais, civis, florestais, sanitaristas, etc.), físicos, geógrafos, geólogos e/ou químicos, etc.; sendo, em sua maioria, especialistas em auditoria, perícia, análise e/ou gestão ambiental, conforme Tabela 1.

Tabela 1: Relatórios de Impactos Ambientais de Usinas de Açúcar e Álcool em MS.

\begin{tabular}{l|l|l}
\hline Usinas & RIMA & Profissionais responsáveis pela elaboração \\
\hline Adecoagro Vale do Ivinhema & Out./2014 & 24 (vinte e quatro) \\
\hline Energética Santa Helena & Ago./2000 & 12 (doze) \\
\hline Raízen Caarapó & Out./2013 & 21 (vinte e um) \\
\hline San Fernando Álcool e Açúcar & Jan./2008 & 06 (seis) \\
\hline Terra Verde Bioenergia & Mai./2010 & 15 (quinze) \\
\hline Usina Naviraí Açúcar e Álcool & 2010 & 26 (vinte e seis) \\
\hline Usina Três Barras & Mar./2012 & 17 (dezessete) \\
\hline
\end{tabular}

Fonte: Adaptado a partir da IMASUL (2014).

Assim, pode-se observar que as Avaliações de Impactos Ambientais (AIA) e os Licenciamentos Ambientais (LA), importantes instrumentos de governança ambiental, são elaborados e analisados, tanto no âmbito federal, quanto no âmbito do estado de Mato Grosso do Sul e nos respectivos municípios, de forma multidisciplinar, visando à prevenção, solução, recuperação e/ou manutenção do meio ambiente.

\section{CONCLUSÕES}

Os problemas ambientais tem se avolumado sobremaneira no país e no mundo, necessitando-se cada vez mais da cooperação e da participação de especialistas das mais diferentes áreas de atuação e conhecimento, exigindo-se a ainda mais da interdisciplinaridade, elementos de fundamental importância para a análise, enfrentamento e resolução de questões ambientais extremamente complexas.

Essas questões são, em sua grande maioria, multidisciplinares, demandando a articulação de várias disciplinas para o enfrentamento de desafios, diante da complexidade de temas 
ambientais que exigem a resposta de profissionais das mais diversas áreas de conhecimento. Assim, dada à sua complexidade, os processos de controle e fiscalização ambiental, ao passar pelo crivo de profissionais de diferentes áreas de atuação, comissão técnica multidisciplinar ou conselho de representantes, estarão mais protegidos.

\section{REFERÊNCIAS}

ALMEIDA NETO, J. V.; OLIVEIRA, A. K. M.; BONONI, V .L. R.. Atuação do Conselho Municipal do Meio Ambiente em Campo Grande (MS): Licenciamento ambiental. Programa de Pós-Graduação em Meio Ambiente e Desenvolvimento Regional. Universidade Anhanguera - Uniderp. Revista Uniara, v.14, n.1, 2011.

BARROS, D. A.; BORGES, L. A. C.; NASCIMENTO, G. O.; PEREIRA, J. A. A.; REZENDE, J. L. P.; SILVA, R. A.. Breve análise dos instrumentos da política de gestão ambiental brasileira. Política \& Sociedade. Florianópolis, v.11, n.22, p. 155-179, 2012.

BARROS, E. C. D. R.; GARCIA, E. M.. Gestão Ambiental em Mato Grosso do Sul: conceitos e práticas. Dourados: Editora UEMS, 2014.

BRASIL. Lei 6.938, de 31 de Agosto de 1981. Dispõe sobre a Política Nacional do Meio Ambiente, seus fins e mecanismos de formulação e aplicação, e dá outras providências. Brasília: MAA, 31 ago 1981.

BUARQUE, C.; FERREIRA, L. C.; JACOBI, P. R.; SOBRAL, M. C.; SAMPAIO, C. A. C.; FERNANDES, V.. (Deb.) Interdisciplinaridade e o enfrentamento aos desafios da sustentabilidade. Sustentabilidade em Debate. Brasília, v.5, n.1, 2014.

CÂMARA, J. B. D.. Governança Ambiental no Brasil: Ecos do passado. Revista de Sociologia e Política. Curitiba, v.21, n.46, p.125-146, 2013.

CARNEIRO, S. M. M.. Interdisciplinaridade: um novo paradigma do conhecimento? Educar. Curitiba, n.10, p.99-109, 1995.

CARVALHO, G. M. B.; MONTEIRO, M. S. L.. Avaliação Ambiental Estratégica e Auditoria Contábil Ambiental como Instrumentos para a Otimização da Política Pública Ambiental no Brasil. REPeC - Rev. Educ e Pesquisa em Contabilidade. Brasília, v.8, n.1, p.54-74, 2014.

CONAMA. Resolução Conama n 001/1986, de 23 de janeiro de 1986. Dispõem sobre os critérios básicos e as diretrizes gerais para uso e implementação da Avaliação de Impacto Ambiental como um dos instrumentos da Política Nacional do Meio Ambiente. Brasília: DOU, 23 jan 1986.

CONAMA. Resolução Conama $n^{\circ}$ 237/1997, de 19 de dezembro de 1997. Dispõe sobre a revisão e complementação dos procedimentos e critérios utilizados para o licenciamento ambiental. Brasília: DOU, 19 dez 1997.

DEPONTI, C. M.. A importância da interdisciplinaridade para compreensão das questões ambientais. REDES Rev. Des. Regional. Santa Cruz do Sul, v.18, n.3, p.240-256, 2013.

IMASUL. RIMAS. Relatórios de Impactos Ambientais. Instituto de Meio Ambiente de Mato Grosso do Sul. Campo Grande: IMASUL, 2014.

\section{LACERDA, A. M. B.; ALMEIDA, L. A. F.. Apontamentos sobre o Licenciamento Ambiental das} Indústrias Sucroalcooleiras no Mato Grosso do Sul. Cuiabá, UFMGS, 2014

LEFF, E.. Complexidade, interdisciplinaridade e saber ambiental. Olhar de professor. Ponta Grossa, v.14, n.2, p.309-335, 2011.

MARANHÃO, T. P. A.. Produção Interdisciplinar de Conhecimento Científico no Brasil: temas ambientais.

Revista Sociedade e Estado. v.25, n.3, p.561-580, 2010. 
MATO GROSSO DO SUL. Lei $\mathbf{n}^{\circ} \mathbf{9 0}$, de 02 de junho de 1980. Dispõe sobre as alterações do meio ambiente, estabelece normas de proteção ambiental e dá outras providências. Cuiabá: DO, 02 jun 1980.

MATO GROSSO DO SUL. Lei $\mathbf{n}^{\circ}$ 702, de 12 de março de 1987. Altera a estrutura básica da Administração Direta do Poder Executivo e dá outras providências. Cuiabá: DO, 12 mar 1987.

MATO GROSSO DO SUL. Lei ${ }^{\circ} \mathbf{3 . 4 0 4}$, de 30 de julho de 2007. Dispõe sobre a localização de estabelecimentos industriais para a produção de açúcar e álcool carburante, para fins de fruição de incentivos ou benefícios fiscais, e dá outras providências. Cuiabá: DO, 30 jul 2007.

MATO GROSSO DO SUL. Lei $\mathbf{n}^{\circ}$ 4.488, de 3 de abril de 2014. Dispõe sobre a reorganização da carreira Fiscalização e Gestão Ambiental, reestrutura o quadro de pessoal do Instituto de Meio Ambiente de Mato Grosso do Sul (IMASUL) e dá outras providencias. Cuiabá: DO, 3 abr 2014.

MATO GROSSO DO SUL. Decreto $\mathbf{n}^{\circ} \mathbf{1 2 . 2 3 1}$, de 3 de janeiro de 2007. Dispõe sobre a estrutura básica e a competência do Instituto de Meio Ambiente de Mato Grosso do Sul - IMASUL. Cuiabá: DO, 3 jan 2007.

MATO GROSSO DO SUL. Decreto n $^{\circ}$ 12.725, de 10 de março de 2009. Estabelece a Estrutura Básica e a Competência do Instituto de Meio Ambiente de Mato Grosso do Sul (IMASUL). Cuiabá: DO, 10 mar 2009.

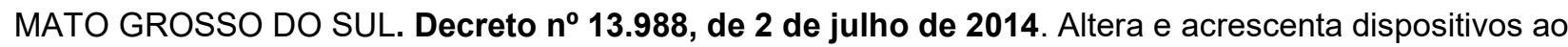
Decreto $n^{\circ} 12.725$, de 10 de março de 2009, e dá outras providências. Cuiabá: DO, 2 jul 2014.

MATO GROSSO DO SUL. Zoneamento Ecológico Econômico do Mato Grosso do Sul: Contribuições técnicas, teóricas, jurídicas e metodológicas. Vol. II. Campo Grande MS: 2008.

MEDEIROS, A. J. R. P.; BARBALHO, K. F.; JERONIMO, C. E. M.. Desafios e a multidisciplinaridade em perícias ambientais. Revista do Centro de Ciências Naturais e Exatas. Santa Maria, v.13, n.13, p.27892796, 2013.

MINAYO, M. S. C.. Disciplinaridade, interdisciplinaridade e complexidade. Emancipação. Ponta Grossa, v.10, n.2, p.435-442, 2010.

MORIN, E.. Os Sete Saberes Necessários à Educação do Futuro. 2 ed. São Paulo: Editora Cortez: 2000.

MORIN, E.. Introdução ao Pensamento Complexo. 3 ed. Lisboa: Piaget, 2001.

NEVES, M. F.; TROMBIN, V. G.. (Coord.) A dimensão do Setor Sucroenergético. Ribeirão Preto: Markestrat, 2014.

OLIVEIRA, M. C.. Gestão Ambiental. Dourados: Editora UEMS, 2014

OLIVEIRA, C. C.; SAMPAIO, R. S. R.. (Orgs.) A economia verde no contexto do desenvolvimento sustentável: a governança dos atores públicos e privados. Contribuições feitas à Jornada Internacional Preparatória para a Rio + 20. 24 e 25 de Junho. Rio de Janeiro: FGV, 2011.

PADILHA, N. S.. O saber ambiental na sua interdisciplinaridade: contribuição para os desafios do direito ambiental. In: ENCONTRO NACIONAL DO CONPEDI. 14. Anais. Fortaleza: CONPEDI, 2010.

PÁDUA, J. B.; DORNELES, T. M.. A prática da contabilidade ambiental na agroindústria sucroenergética. Revista Ciências Sociais em Perspectiva. v.13, n.24, 2014.

PEGADO, E. A. C.; BARBOSA, E. M.. Audiências Públicas Ambientais e Racionalidade: Perspectivas e Desafios. Holos. v.1, n.29, 2013

PHILIPPI JUNIOR, A.; SOBRAL, M. C.; FERNANDES, V.; SAMPAIO, C. A. C.. Desenvolvimento sustentável, interdisciplinaridade e Ciências Ambientais. RBPG. Brasília, v.10, n.21, p.509-533, 2013.

RAYNAUT, C.. Interdisciplinaridade: mundo contemporâneo, complexidade e desafios à produção e à aplicação de conhecimentos. Barueri: Manole, 2011.

RAYNAUT, C.. Meio ambiente e desenvolvimento: construindo um novo campo do saber a partir da perspectiva interdisciplinar. Desenvolvimento e Meio Ambiente. Curitiba, n.10, p.21-32, 2004. 
RODRIGUES, G. S. S. C.. A análise interdisciplinar de processos de Licenciamento Ambiental no estado de Minas Gerais: conflitos entre velhos e novos paradigmas. Sociedade \& Natureza, Uberlândia, v.22, n.2, p.267-282, 2010.

SANTAMARINA, A.; CUNHA NETO, F. R.. Contextualização dos profissionais habilitados nas engenharias nos processos de licenciamentos ambientais. Enciclopédia Biosfera. Goiânia, v.6, n.10, 2010. 